\title{
An Investigation on Self-Compacting Concrete Using Ultrafine Natural Steatite Powder as Replacement to Cement
}

\author{
P. Kumar, ${ }^{1}$ K. Sudalaimani, ${ }^{2}$ and M. Shanmugasundaram ${ }^{3}$ \\ ${ }^{1}$ Department of Civil Engineering, P.S.R. Engineering College, Sivakasi, Tamil Nadu 626140, India \\ ${ }^{2}$ Department of Civil Engineering, Thiagarajar College of Engineering, Thiruparankundram, Madurai, Tamil Nadu 625015, India \\ ${ }^{3}$ Structural Engineering Division, School of Mechanical and Building Sciences, VIT University, Chennai Campus, Chennai, \\ Tamil Nadu 600127, India
}

Correspondence should be addressed to P. Kumar; kumarponnudurai.civil@gmail.com

Received 18 April 2017; Accepted 2 July 2017; Published 2 August 2017

Academic Editor: Prinya Chindaprasirt

Copyright (C) 2017 P. Kumar et al. This is an open access article distributed under the Creative Commons Attribution License, which permits unrestricted use, distribution, and reproduction in any medium, provided the original work is properly cited.

An experimental investigation was made on flow properties and compressive strength of self-compacting concrete (SCC) with ultrafine natural steatite powder (UFNSP) as replacement to cement. The tests were conducted on specimens with 5\%, 10\%, 15\%, $20 \%$, and $25 \%$ of replacement of UFNSP to the weight of cement and compared to the control specimens. The flow properties of all specimens were tested and checked for their limit with the existing guidelines. The compressive strength test was done on all specimens for strength of 7 days, 14 days, 28 days, and 56 days. The hardened samples were tested for their microstructural behavior and the elements $\mathrm{Mg}$, Ca, and Si were mapped. Through mapping, the formations of M-S-H along with C-S-H are observed. The results show that the addition of UFNSP influences the flow property, by reducing the flow, and increases the compressive strength till 20\% replacement. Further the addition of UFNSP increases the denseness of microstructure of the specimens thus resulting in the strength increment.

\section{Introduction}

The self-compacting concrete (SCC), also known as selfconsolidating concrete, is in the limelight for the last two decades in construction industry. Self-compacting concrete (SCC) is a concrete which can be placed and compacted into every corner of formwork purely by means of its self-weight by eliminating the need of external energy. So it does not require compaction at site or concrete plants. It has been developed in Japan to improve the durability and uniformity of concrete [1]. The mix composition is chosen to satisfy all performance criteria for the concrete in both the fresh and hardened states. To achieve this, fly ash and silica fume were used as mineral admixtures, and super plasticizers were used in mix as chemical admixtures for design of concrete. In this regard, mass of fine aggregate is typically equal or greater when compared to coarse aggregate. Selection of coarse aggregate size also has an impact on requirement of selfcompacting concrete. The development of SCC and its results on theoretical and experimental aspects were reviewed in various studies [2-4]. The methods of manufacturing of SCC initially had high content of paste; later on, researches were made to reduce the paste content and achieve strength $[5,6]$. Due to the high content of water and voids, it has become important to look into the workability and segregation behavior of SCC $[7,8]$. The important property of a SCC is to have workable and segregation resistant concrete which can flow through the reinforcement without any external vibrations or compactions [9]. The bond strength of reinforced bars and the SCC are higher when compared to that of normal concrete which also made the SCC more predominant material [10]. There were two types of usage of materials in SCC; one is as a pozzolanic replacement and the other one is filler. In this study ultrafine natural steatite powder (UFNSP) is used as cementitious replacement to cement. The steatite was used as insulators in ceramics, due to its high thermal resistivity. Its other major uses are in carving and sculpture industry. It is a proven durable raw material in refractory industry. In 
TABLE 1: Properties of UFNSP.

\begin{tabular}{lcc}
\hline & UFNSP & Cement \\
\hline \multicolumn{3}{c}{ Physical properties } \\
\hline Blaine surface area $\left(\mathrm{m}^{2} / \mathrm{Kg}\right)$ & 750 & 380 \\
Particle mean Dia $(\mu \mathrm{m})$ & $<5$ & $<32$ \\
Density & 2.7 & 3.1 \\
Loss of ignition & $3.33 \%$ & $2 \%$ \\
\hline \multicolumn{3}{c}{ Chemical properties } \\
$\mathrm{SiO}_{2}$ & $62.67 \%$ \\
$\mathrm{Al}_{2} \mathrm{O}_{3}$ & $0.24 \%$ & $23 \%$ \\
$\mathrm{MgO}$ & $33.26 \%$ & $4.20 \%$ \\
$\mathrm{Fe}_{2} \mathrm{O}_{3}$ & $0.30 \%$ & $0.20 \%$ \\
$\mathrm{CaO}$ & $0.20 \%$ & $1.20 \%$ \\
\hline
\end{tabular}

terms of steatite the grinded powder was already proved to be good replacement to cement until 15\% [11, 12]. Durability and strength of concrete increase with replacement of steatite powder to certain limit [12-14]. The phase of steatite is crystalline which belongs to magnesium metasilicate from talc mineral based on the following reaction [15]:

$$
3 \mathrm{MgO} \cdot 4 \mathrm{SiO}_{2} \cdot \mathrm{H}_{2} \mathrm{O} \longrightarrow 3 \mathrm{MgSiO}_{3}+\mathrm{SiO}_{2}+\mathrm{H}_{2} \mathrm{O}
$$

And this reaction supports the M-S-H formation. Generally the earlier studies show that the M-S-H gel has amorphous phase $[11,12]$. The magnesium-rich binders can lead to low $\mathrm{pH}$ binding system which has wide range of applications in adverse concreting condition, and also this magnesium richness leads to early strength development and durability [16]. The present proposal will cover the area on development of SCC based on magnesium-rich steatite powder replacement and its mechanical behavior.

\section{Materials, Mix Proportions, and Experimental Investigation}

2.1. Materials Used in This Study. Ordinary Portland cement of grade 43 conforming to Indian Standard (IS) 12269-1987 was used and the properties were listed in Table 1. The UFNSP of less than 5 microns similar to that of earlier studies [11-14] is used and the physical and chemical properties were presented in Table 1. UFNSP was used as pozzolanic replacement in this study. The river sand procured from Tamil Nadu Minerals Limited (TAMIN) with the specific gravity of 2.65 and passing through $2.36 \mathrm{~mm}$ sieve was used. Crushed granite was used as coarse aggregate with a maximum nominal size of $12 \mathrm{~mm}$ and bulk density of $1640 \mathrm{~kg} / \mathrm{m}^{3}$. The normal potable water was used for mixing and curing process. Polycarboxylic ether based superplasticizer sky 8233 and viscosity modifier, Mastermatrix VMA 362, were used in this study as admixtures to maintain the workability.

2.2. Mix Proportion. The mix proportion was finalized based on trial and error process conforming to the EFNARC guidelines [17], and the target strength to be achieved was fixed as $25 \mathrm{MPa}$. The ratio of powder: fine aggregate: coarse

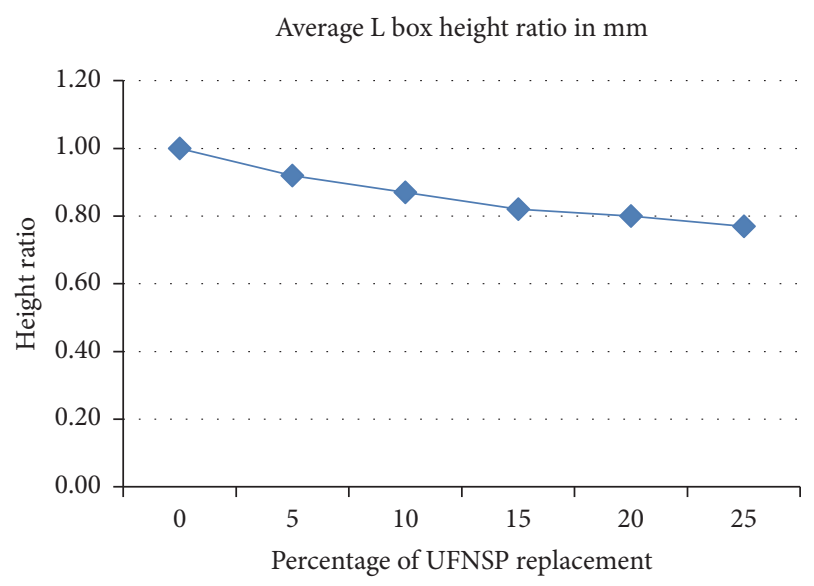

Average L box height in $\mathrm{mm}$

FIGURE 1: Results on $L$ box test.

aggregate was maintained as $1: 1.8: 1.9$. The water/powder ratio was fixed as 0.8 [17]. To achieve the workability $2 \%$ superplasticizer and $0.4 \%$ viscosity modifier were added, and the addition was carried out with respect to weight of cement.

2.3. Experimental Investigation. The workability and flow properties of the fresh concrete were examined by L box test, J-ring test, V-funnel flow test, slump flow test, and T50 flow timing conforming to EFNARC guidelines [17]. The compressive strength of the hardened specimens was tested on cubes of size $150 \mathrm{~mm} \times 150 \mathrm{~mm} \times 150 \mathrm{~mm}$ conforming to specification of Indian Standard (IS) 10086: 1982 and the tests were carried out in accordance with IS 516: 1959 (reaffirmed 2004) in hydraulic compression testing machine of $2000 \mathrm{kN}$ capacity. The microstructural behavior of the specimens is studied by scanning electron microscopy. Samples for scanning electron microscopy (SEM) analysis are taken near the surface (0-1 mm depth) of specimens. Microstructural studies utilized SEM (ZEISS) equipped with EDAX analyzer for microstructural observations of the surfaces, which is coated with evaporated copper for examination. SEM analysis is done at a maximum magnification of $1000 \mathrm{x}$ with energy $20 \mathrm{keV}$ and a high resolution of $3.5 \mathrm{~nm}$. For this analysis, samples of size $10 \mathrm{~mm}$ cubes were cut with a saw cutter.

\section{Results and Discussion}

The results were observed on the fresh and hardened state of concrete. The tests were carried out to ascertain the flow properties of fresh concrete, compressive strength on hardened concrete, and its respective microstructural behavior.

3.1. Workability and Flow Properties of Fresh Concrete. The results for "L" box test were presented in Table 2 and Figure 1. The results show that the addition of UFNSP as replacement to cement increases the water requirement by reducing the height ratio. The average value of " $\mathrm{L}$ " box height for 25\% UFNSP replacement crosses the safe limit of EFNARC permissible limit. In comparison with the control 
TABLE 2: Results on flow properties of fresh concrete.

\begin{tabular}{lccccccc}
\hline S. number & Mix Ids & $\begin{array}{c}\text { Percentage } \\
\text { replacement of } \\
\text { UFNSP }\end{array}$ & $\begin{array}{c}\text { Average L box } \\
\text { height ratio }\end{array}$ & $\begin{array}{c}\text { Average J-ring } \\
\text { height (mm) }\end{array}$ & $\begin{array}{c}\text { Average } \\
\text { V-funnel flow } \\
\text { time in sec }\end{array}$ & $\begin{array}{c}\text { Average slump } \\
\text { flow diameter in } \\
\text { mm }\end{array}$ & $\begin{array}{c}\text { Average T50 cm } \\
\text { slump flow in } \\
\text { sec }\end{array}$ \\
\hline 1 & SCCCS & 0 & 1.00 & 7.88 & 7.90 & 710.00 & 2.60 \\
2 & SCC5 & 5 & 0.92 & 7.93 & 9.20 & 700.00 & 2.70 \\
3 & SCC10 & 10 & 0.87 & 8.23 & 9.50 & 680.00 & 3.20 \\
4 & SCC15 & 15 & 0.82 & 8.45 & 10.40 & 672.00 & 4.00 \\
5 & SCC20 & 20 & 0.80 & 8.73 & 11.20 & 650.00 & 4.50 \\
6 & SCC25 & 25 & 0.77 & 9.33 & 11.80 & 630.00 & 5.00 \\
\hline
\end{tabular}

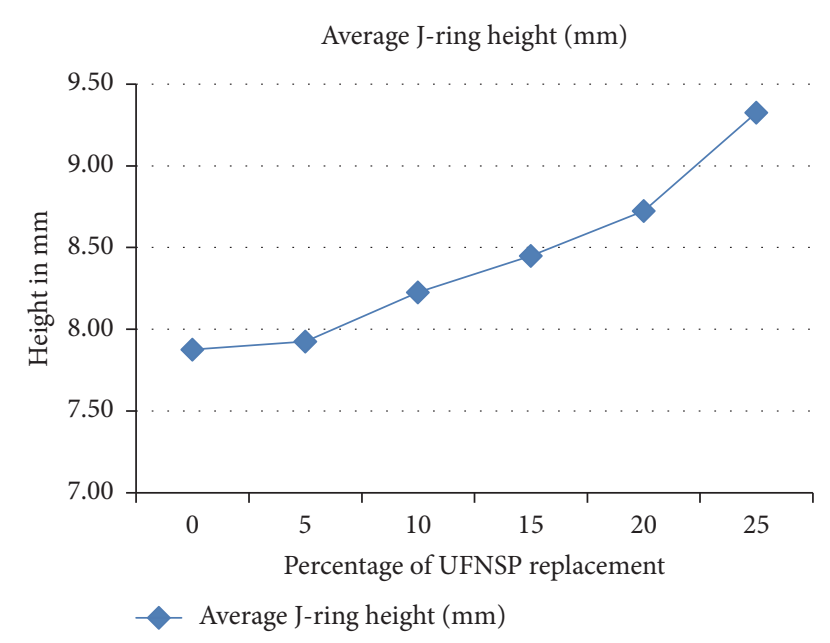

FIGURE 2: Results on J-ring test.

specimen (SCCCS), specimens SCC5, SCC10, SCC15, SCC20, and SCC25 lose their height ratio by $8 \%, 13 \%, 18 \%, 20 \%$, and $23 \%$, respectively. The results show that there was a sudden reduction in height ratio between 0 and $15 \%$ replacements and then the ratio gets stabilized and this is due to the fact that after certain percentage of replacement the cement UFNSP reaction was lesser.

The results on J-ring test on fresh self-compacting concrete were presented in Table 2 and Figure 2. The test results shows that the height of fresh concrete in J-ring rises by $0.63 \%, 4.4 \%, 7.3 \%, 10.79 \%$, and $18.41 \%$ for the specimens SCC5, SCC10, SCC15, SCC20, and SCC25, respectively, in comparison with SCCCS. From Figure 2 it was observed that height increment is not notable for specimen with $5 \%$ of UFNSP replacement. From 5\% to $20 \%$ of UFNSP replacement the height gradually increases from $7.93 \mathrm{~mm}$ to $8.73 \mathrm{~mm}$; with the replacement of $25 \%$ the height gets a steep increase to $9.33 \mathrm{~mm}$. Even though the height rises the values were within the permissible limit which is $0-10 \mathrm{~mm}$.

The results on "V"-funnel test on fresh self-compacting concrete specimens were presented in Table 2 and Figure 3. The results show that the time period for flow of fresh concrete through the " $V$ "-funnel increases as the replacement percentage of UFNSP increases. The minimum time is observed at SCCCS specimen with flow period as 7.90 seconds and maximum time period for flow was observed

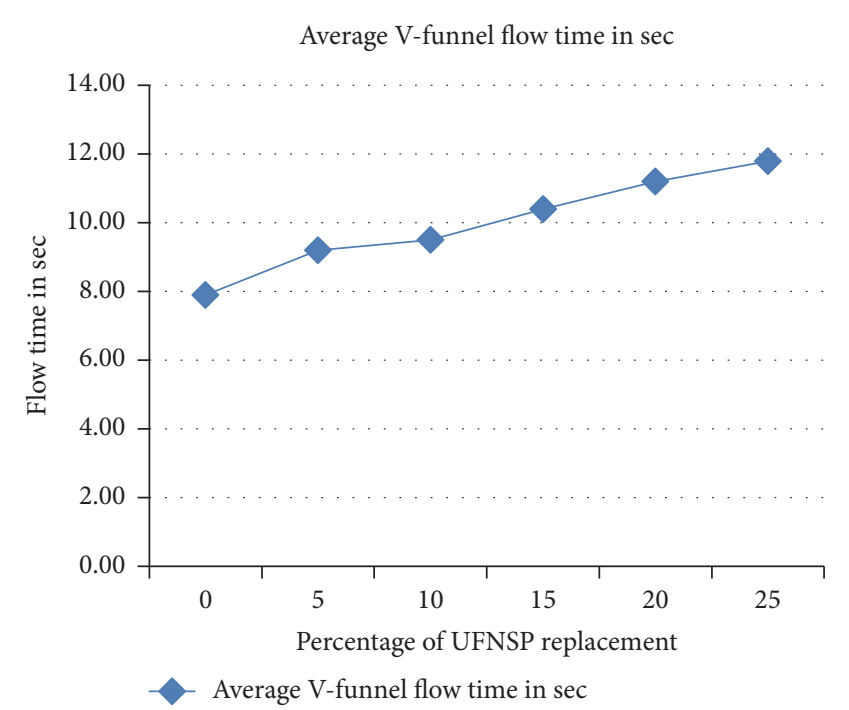

Figure 3: Results on V-funnel flow test.

at SCC25 with 11.80 seconds. The flow timing increases almost linearly which can be observed from Figure 3 . The flow period for SCC5, SCC10, SCC15, SCC20, and SCC25 increases by $16.46 \%, 20.25 \%, 31.65 \%, 41.77 \%$, and $49.37 \%$ in comparison to SCCCS specimen. The values lie well within the permissible limit for a typical self-compacting concrete. The actual permissible limit given by EFNARC is $0-25 \mathrm{Sec}$.

The slump flow values and the corresponding $T 50 \mathrm{~cm}$ test results were presented in Table 2 and Figures 4 and 5. The results show that the slump value reduces as the percentage replacement of UFNSP increases, which shows the UFNSP has an impact on the workability of SCC. The SCCCS specimen has the maximum value as observed by the other tests earlier and the lowest value was observed at SCC25 measuring $630 \mathrm{~mm}$. The flow of SCC5, SCC10, SCC15, SCC20, and SCC25 reduces by 1.41\%, 4.23\%, 5.35\%, 8.45\%, and $11.27 \%$ with reference to SCCCS. The time period of flow for T50 test was presented in Figure 5. The time for spreading increases and the time for SCC25 is longer with its value as $5 \mathrm{sec}$. As the addition of UFNSP reduces the workability, the flow gets affected and hence the delay in spreading occurs. The spreading time increases as $3.85 \%$, $23.08 \%, 53.85 \%, 73.08 \%$, and $92.31 \%$ for SCC5, SCC10, SCC15, SCC20, and SCC25 in comparison with SCCCS. Even though 
TABLE 3: Compressive strength of hardened concrete cubes.

\begin{tabular}{|c|c|c|c|c|c|}
\hline \multirow{2}{*}{ S. number } & \multirow{2}{*}{ Mix Ids } & \multicolumn{4}{|c|}{ Average compression strength in $\mathrm{MPa}$} \\
\hline & & 7 days & 14 days & 28 days & 56 days \\
\hline 1 & SCCCS & 21.80 & 25.27 & 26.60 & 26.90 \\
\hline 2 & SCC5 & 27.95 & 31.20 & 32.50 & 32.65 \\
\hline 3 & SCC10 & 31.50 & 33.61 & 34.30 & 34.40 \\
\hline 4 & SCC15 & 34.20 & 35.90 & 36.20 & 36.30 \\
\hline 5 & SCC20 & 29.07 & 31.01 & 32.30 & 32.37 \\
\hline 6 & SCC25 & 22.80 & 25.44 & 26.50 & 26.80 \\
\hline
\end{tabular}

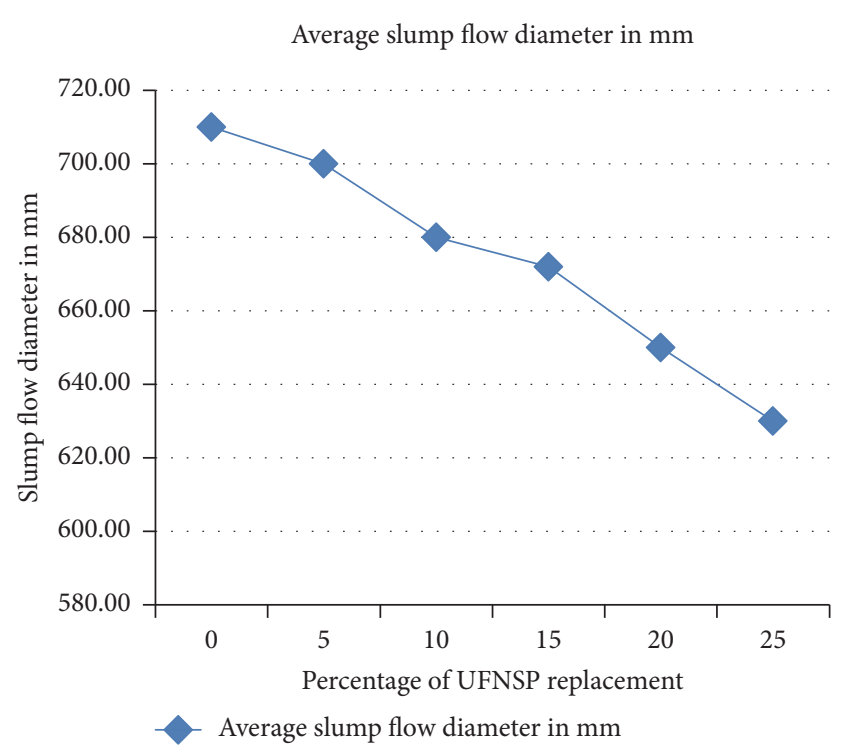

FIGURE 4: Results on slump flow test.

the slump value decreases and the T50 test time increases the values are all well within the limit and show typical selfcompacting concrete characteristics as indicated by EFNARC guidelines.

The observations shows that the water requirement was more in samples with UFNSP as replacement, and this is due to the fact that the $\mathrm{M}-\mathrm{S}-\mathrm{H}$ binder matrix with $\mathrm{MgO}$ presence has large water requirement due to texture, size, and shape of the particles [18]. This higher water requirement is also due to the reactive magnesia [19], a part in the UFNSP. From the tests on workability, even though it was observed that the replacement of UFNSP reduces the flow, almost all specimen lies within the typical limit as specified by EFNARC, and hence the replacement can be done until 25\% without any effect on SCC limiting values.

3.2. Compressive Strength on Hardened Concrete at Various Ages. The compressive strength is tested on hardened concrete and the results are presented in Table 3 and Figure 6. The results show that at early ages all the replacement specimens show higher strength gain than the control specimens. The strength attainment of SCCCS, SCC5, SCC10, SCC15, SCC20, and SCC25 was $82 \%, 86 \%, 92 \%, 94 \%, 90 \%$, and $86 \%$,

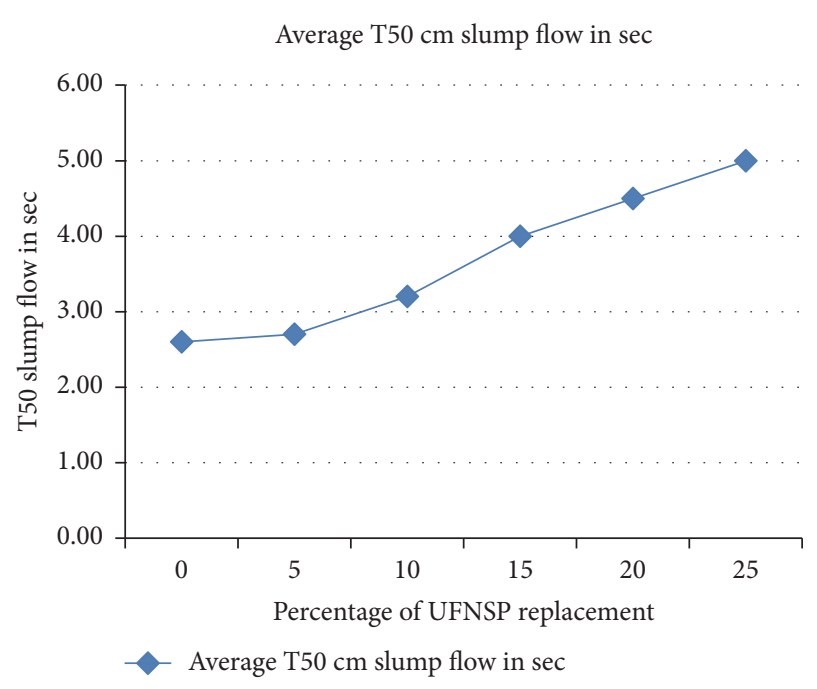

FIGURE 5: Results on T50 slump flow test.

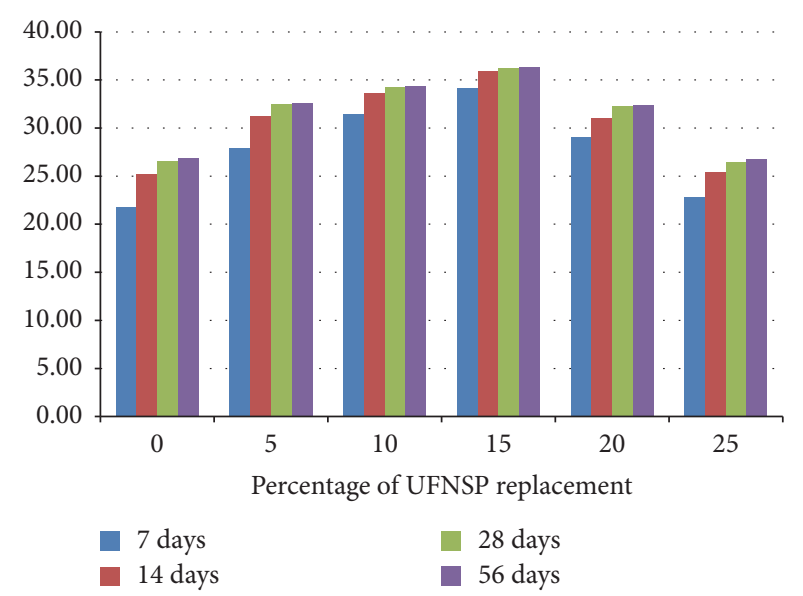

FIGURE 6: Results on average compressive strength test on 28 days.

respectively, on 7 days and 95\%, 96\%, 98\%, 99\%, 97\%, and $95 \%$ on 14 days. Through this, the SCC5 and SCC10 specimens are attaining $90 \%$ and above of designed strength on 7 days, which may be a notable parameter. The 7 days' test shows that the SCC5, SCC10, SCC15, SCC20, and SCC25 has strength increment of about $28.21 \%, 44.50 \%, 56.88 \%, 33.35 \%$, and $4.59 \%$, respectively, when compared to SCCCS. From the 


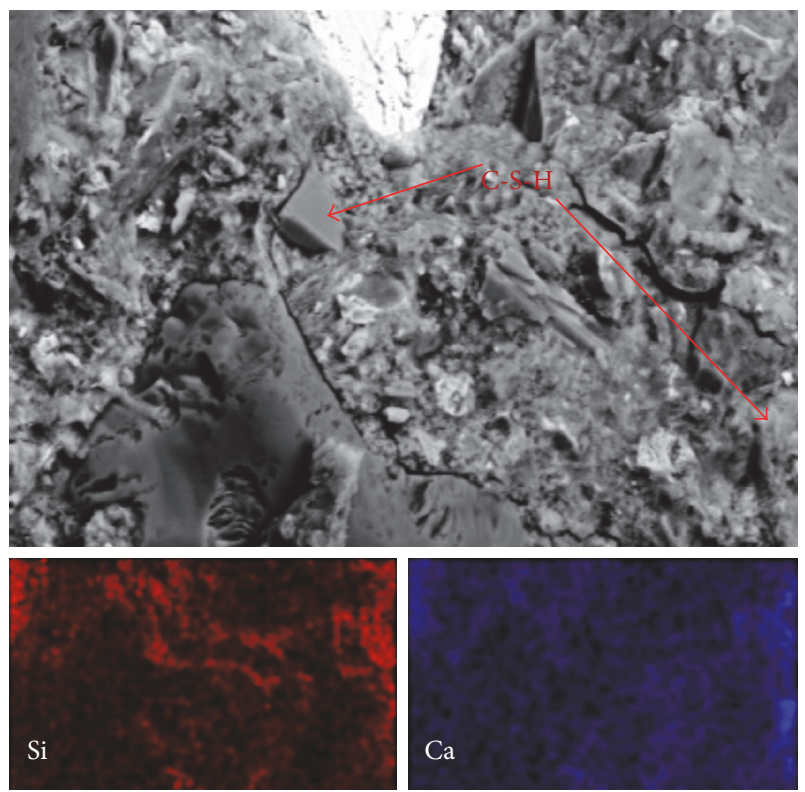

Figure 7: SEM image and its EDAX mapping on $\mathrm{Si}, \mathrm{Mg}$, and $\mathrm{Ca}$ of control specimen (CS).

results on 14 days' test it was evident that the SCC5, SCC10, SCC15, SCC20, and SCC25 have strength increment of about $23.47 \%, 33.30 \%, 42.07 \%, 22.71 \%$, and $0.67 \%$, respectively, in comparison with SCCCS. The 28 days' compressive strength for SCC5, SCC10, SCC15, and SCC20 has strength gain of about $22.18 \%, 28.95 \%, 36.09 \%$, and $21.43 \%$, respectively. The SCC25 specimens have a strength reduction of about $0.38 \%$ on 28 days in comparison with SCCCS. The 56 days' compressive strength for SCC5, SCC10, SCC15, and SCC20 has strength gain of about $21.38 \%, 27.88 \%, 34.94 \%$, and $20.33 \%$, respectively. The SCC25 specimens have a strength reduction of about $0.37 \%$ on 56 days in comparison with SCCCS. Through the observations it was evident that until 14 days the strength of all replacement specimens increases. From 28 days the strength of SCC25 is almost similar to that of SCCCS and there is very little strength loss for SCC25 on 28 and 56 days' tests. The strength gain is due to the presence of right proportion of M-S- and C-S-H [20]. The concrete attains its strength through the UFNSP; the reason behind this is the presence of $\mathrm{Mg}$ and reduced particle size of UFNSP, which facilitates the intrusion of particle in cement matrix [11-14]. The higher hydration rate is the main cause of early age strength attainment [21]. From the result it was clear that the strength attainment can be achieved until 20\% replacement. The specimen with 25\% UFNSP replacement is almost equal to and little lesser than SCCCS specimens on 28 days and 56 days.

3.3. Microstructure and Elemental Mapping on 56 Days' Hardened Specimens. The scanning electron microscopy analysis on the microstructure of the concrete specimen at 56 days and its relevant mapping for silica $(\mathrm{Si})$, magnesium $(\mathrm{Mg})$, and Calcium $(\mathrm{Ca})$ of those specimens are presented through Figures 7-12. The elemental EDAX mapping is carried out

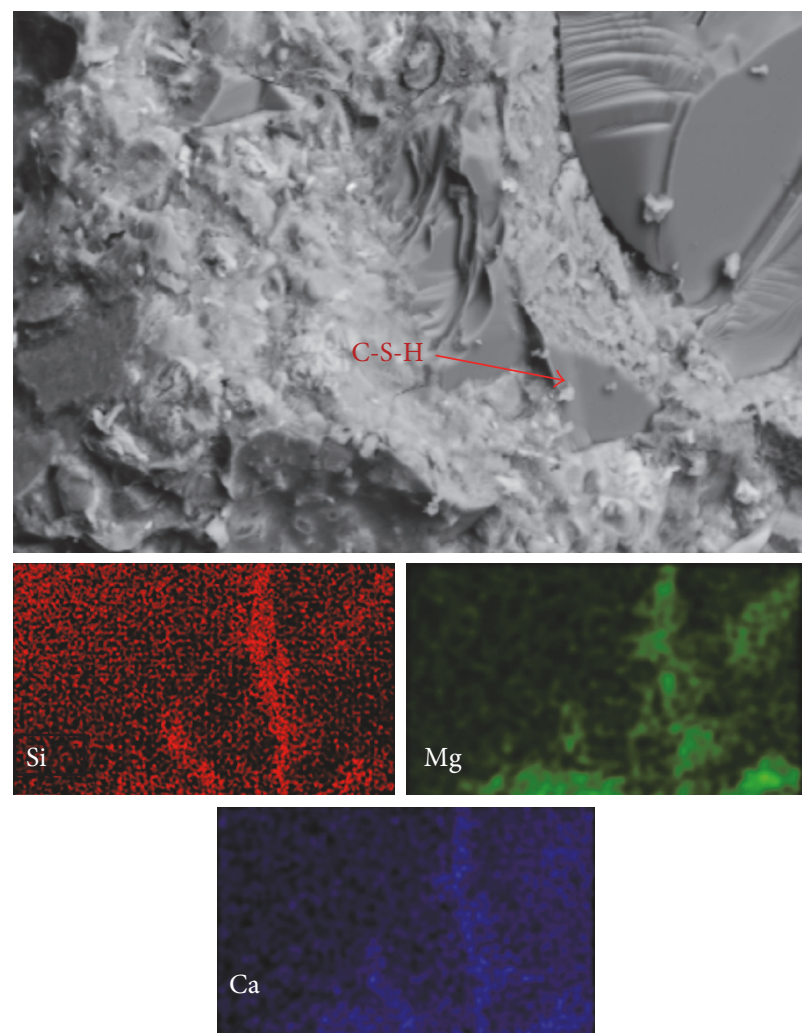

FIGURE 8: SEM image and its EDAX mapping on $\mathrm{Si}, \mathrm{Mg}$, and $\mathrm{Ca}$ of SCC-5.

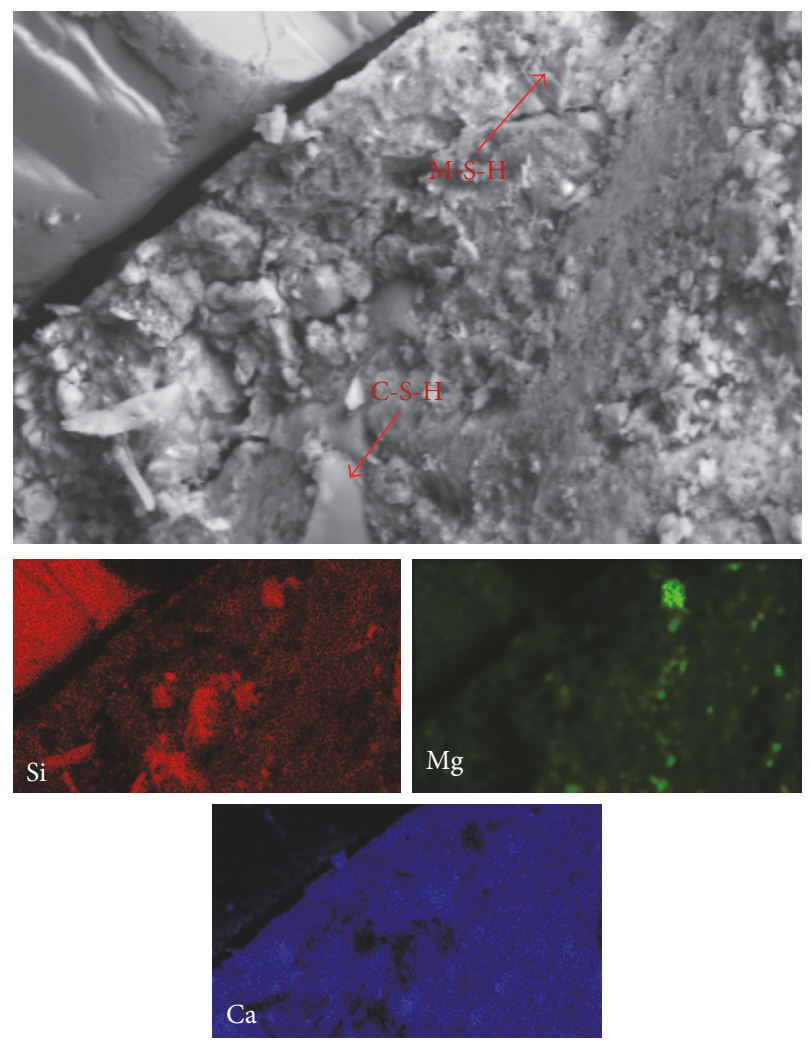

FIGURE 9: SEM image and its EDAX mapping on $\mathrm{Si}, \mathrm{Mg}$, and $\mathrm{Ca}$ of SCC-10. 


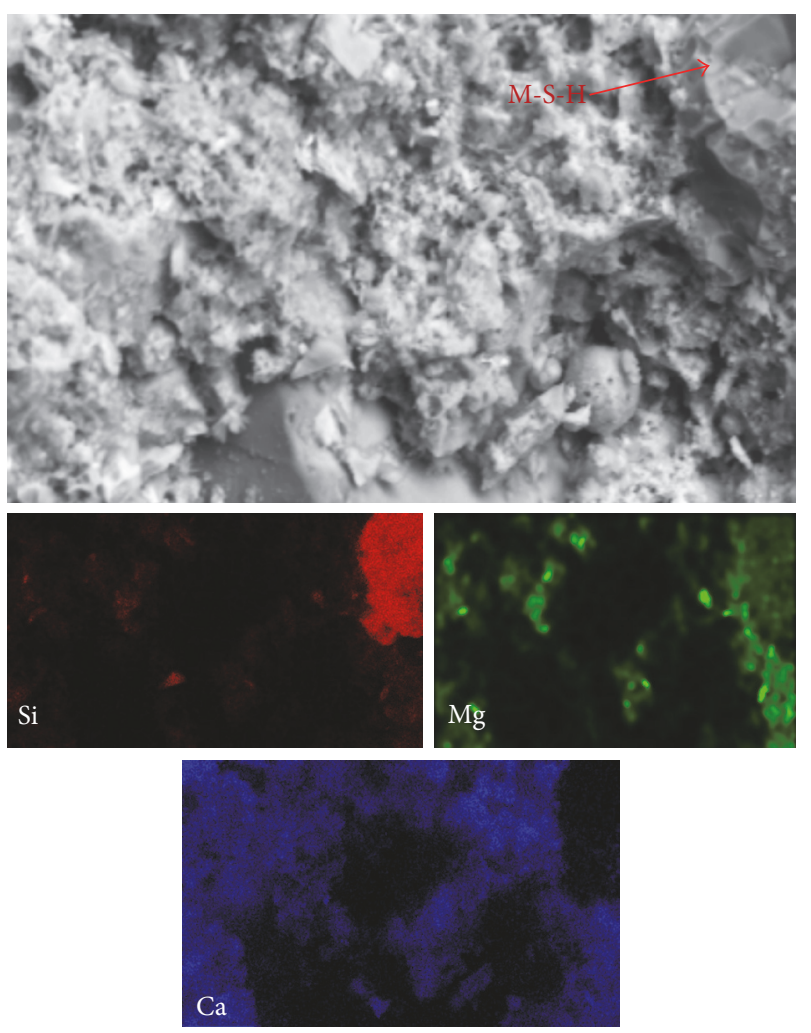

FIGURE 10: SEM image and its EDAX mapping on $\mathrm{Si}, \mathrm{Mg}$, and $\mathrm{Ca}$ of SCC-15.
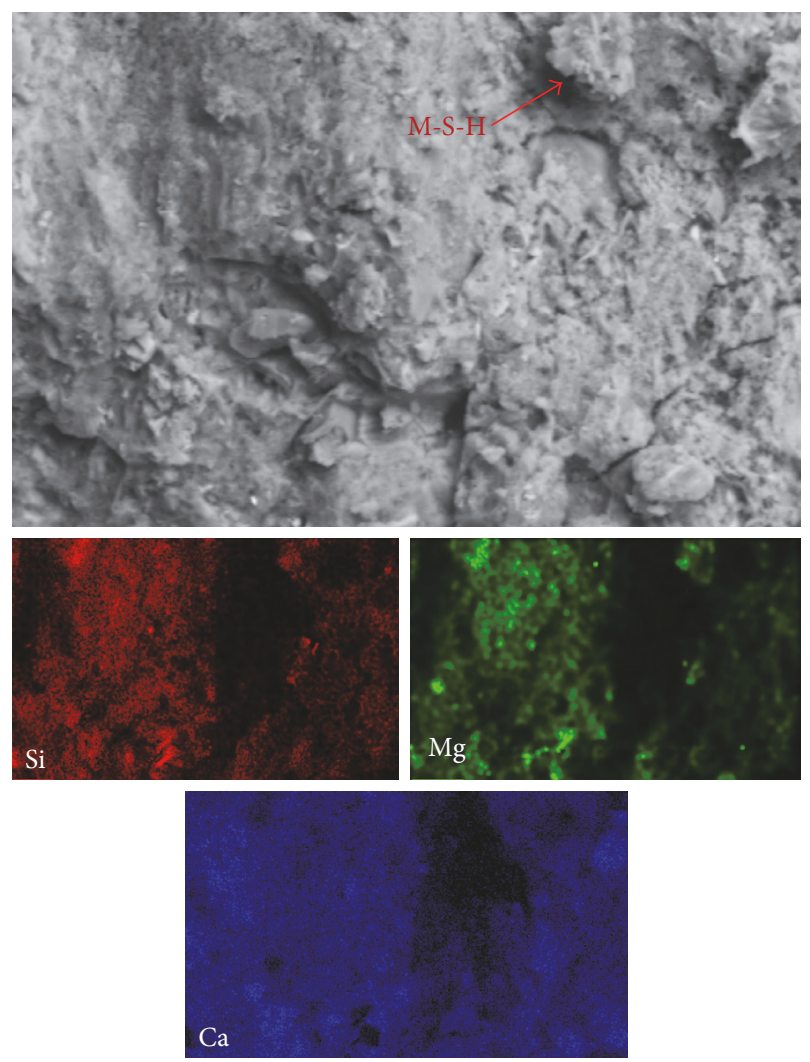

FIGURE 11: SEM image and its EDAX mapping on Si, Mg, and Ca of SCC-20.

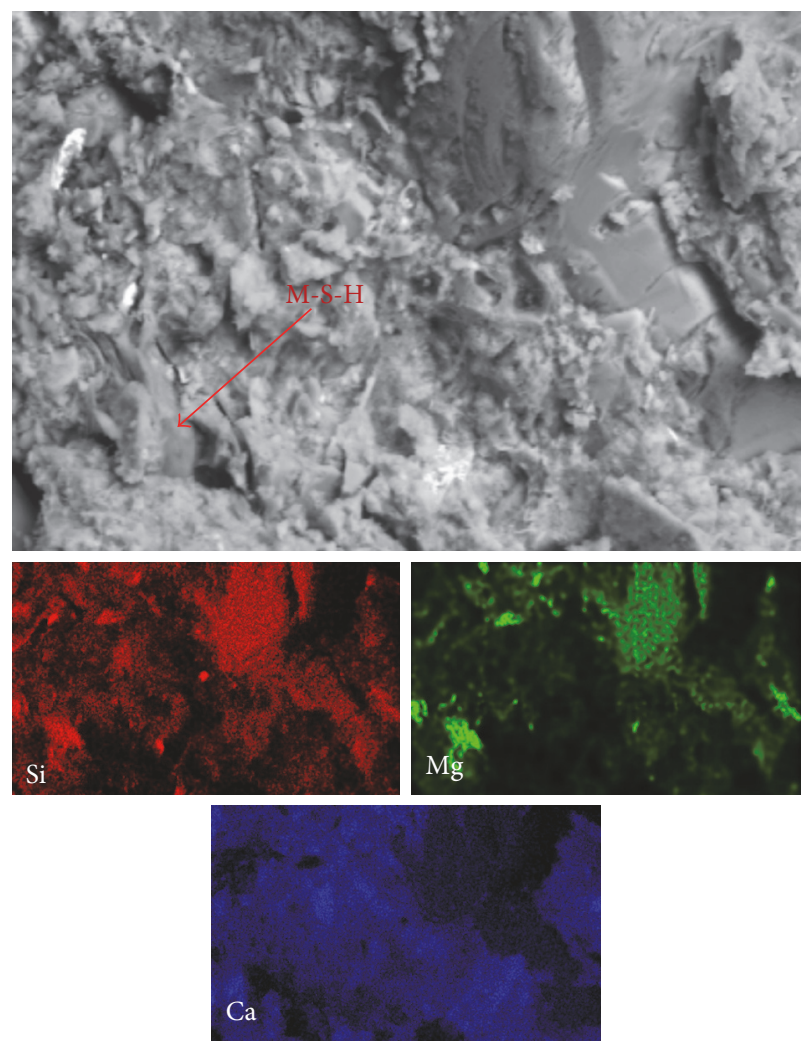

FIgUre 12: SEM image and its EDAX mapping on $\mathrm{Si}, \mathrm{Mg}$, and $\mathrm{Ca}$ of SCC-25.

to ascertain whether the addition of UFNSP has genuine effect on the strength development. The microstructural evolution was observed to be similar on all samples. Figure 7 shows the microscopy image of control specimen and its relevant mapping. This shows conventional specimen has no traces of magnesium elements. The formation of calcium silicate hydrates is noted. Figure 8 shows the images of SCC5 specimen has the traces of C-S-H along with M-S-H. The presence of magnesium is very limited when compared to calcium and this is due to the lesser replacement of UFNSP. The microscopy and mapping images were shown in Figure 9, and it is observed that the denseness of $\mathrm{M}-\mathrm{S}-\mathrm{H}$ formation is increasing and it is validated through the mapping, and a possible trace of magnesium hydroxide is also noted. Figure 10 shows the results of SCC15, and it is observed that the formation of $\mathrm{M}-\mathrm{S}-\mathrm{H}$ is more prominent and denser. The solidity of the magnesium silicate has increased widely in comparison with the specimens earlier, and also few spots of free calcium are traced which may cause a break point on strength gain. The maximum strength is observed at SCC15 which is to be noted at this point. Figure 11 shows the result images for SCC20 specimen and it shows large formation of magnesium silicate along with the calcium silicates, and the microstructure indicates positive attainment of microstructural evolution of control specimen, but not in comparison with SCC15 specimen. Figure 12 shows the microscopy and mapping images of SCC25 specimens; the microstructure of SCC25 was almost similar to that of SCCCS specimens. 
In SCC25 it is noted that the magnesium silicates tend to break down to tiny M-S-H crystal which is identified through mapping, and this phenomenon causes the major strength reduction which is not observed in earlier specimens. In all the specimens it is noted that both magnesium based hydration products and calcium based hydration products have a vital role in establishing the strength gain.

From the above observations it can be ascertained that magnesium and magnesium based products are stable in all specimens, and it is also shown that when water exhausts the reaction of components end thus stabilizes its microstructure and attains early age strength in case of replacement up to $20 \%$, this reaction product takes up space around magnesium compounds thus giving denser structure [22]. The magnesium based hydration products were found to be present in regions devoid of other elements, suggesting the presence of $\mathrm{Mg}$ crystals [23]. The observation shows that the M-S-H was less crystalline as observed and when this becomes more crystalline then the strength gain is reduced [24]. The process of increasing the $\mathrm{Mg}(\mathrm{OH})_{2}$ and other magnesium hydration products improve the mechanical strength and specimen's microstructure as it is observed [21]. The addition of UFNSP has induced the magnesium based hydration products, and the results were little bit contrary to earlier studies [12, 13]. The contradiction is due to the increased water usage in current study through which the brucite development is accommodated in the pores. In this study as there are larger voids due to the higher water content and other admixtures, the $\mathrm{Mg}(\mathrm{OH})_{2}$ which is higher in density than that of $\mathrm{Ca}(\mathrm{OH})_{2}$ gets enough space to accommodate itself hence paving the way to good strength and microstructure, even at $25 \%$ replacement, which was not so in earlier studies [11, 12]. From the above study it can be ascertained that the usage of UFNSP will enhance the strength parameters and denser microstructural bond. The replacement percentage of UFNSP shall be maintained at $15 \%$ for maximum strength attainment, but still the $25 \%$ replacement gives strength similar to control specimen which shows that the replacement shall be carried out up to $25 \%$.

\section{Conclusions}

From the present study it can be concluded that the replacement of UFNSP in self-compacting concrete system can have an influence on the workability, flow of fresh concrete, compressive strength of hardened concrete, and microstructural properties. There was decrease in flow properties of SCC with increase in addition of UFNSP. The entire replacement percentage exhibits safer limit for the SCC, but the specimens with $25 \%$ of UFNSP replacement reach the limit where the typical limit ends, which confirms that further replacement is not possible in terms of flow properties. The early age strength attainment is seen in samples SCC5, SCC10, SCC15, and SCC2 0 even on 7 days' test where more than the target strength is achieved. The maximum strength is achieved in SCC15 specimens. The strength enhancement is seen on all replacement specimens, wherein the strength of SCC25 specimens is almost equal to that of SCCCS. The microstructures of SCC10, SCC15, and SCC20 are denser and show denser magnesium hydroxide which has an effect on strength improvement. Further magnesium and silicate are mapped, which shows the dispersion over the surface and forms denser structures. The reduced strength of SCC25 is due to the higher magnesium content. From the investigation and discussion it is concluded that the replacement of UFNSP should be maintained below 20\% and the UFNSP will enhance the strength parameters of the SCC.

\section{Conflicts of Interest}

The authors declare that there are no conflicts of interest regarding the publication of this paper.

\section{References}

[1] H. Okamura and M. Ouchi, "Self-compacting concrete," Journal of Advanced Concrete Technology, vol. 1, no. 1, pp. 5-15, 2003.

[2] H. J. H. Brouwers and H. J. Radix, "Self-compacting concrete: Theoretical and experimental study," Cement and Concrete Research, vol. 35, no. 11, pp. 2116-2136, 2005.

[3] P. L. Domone, "Self-compacting concrete: An analysis of 11 years of case studies," Cement and Concrete Composites, vol. 28, no. 2, pp. 197-208, 2006.

[4] P. L. Domone, "A review of the hardened mechanical properties of self-compacting concrete," Cement and Concrete Composites, vol. 29, no. 1, pp. 1-12, 2007.

[5] N. Su, K.-C. Hsu, and H.-W. Chai, "A simple mix design method for self-compacting concrete," Cement and Concrete Research, vol. 31, no. 12, pp. 1799-1807, 2001.

[6] N. Su and B. Miao, "A new method for the mix design of medium strength flowing concrete with low cement content," Cement and Concrete Composites, vol. 25, no. 2, pp. 215-222, 2003.

[7] M. F. Granata, "Pumice powder as filler of self-compacting concrete," Construction and Building Materials, vol. 96, pp. 581590, 2015.

[8] EFNARC, Specifications and Guidelines for Self-compacting Concrete, Association House, Surrey, UK, 2002.

[9] E. Güneyisi, M. Gesoğlu, S. Al-Rawi, and K. Mermerdaş, "Effect of volcanic pumice powder on the fresh properties of selfcompacting concretes with and without silica fume," Materials and Structures/Materiaux et Constructions, vol. 47, no. 11, pp. 1857-1865, 2014.

[10] N. Verma and A. K. Misra, "Bond characteristics of reinforced TMT bars in self compacting concrete and normal cement concrete," Alexandria Engineering Journal, vol. 54, no. 4, pp. 1155-1159, 2015.

[11] M. Shanmugasundaram and K. Sudalaimani, "An investigation on high performance concrete with ultra fine natural steatite powder," Information, vol. 17, no. 6 A, pp. 2267-2277, 2014.

[12] K. Sudalaimani and M. Shanmugasundaram, "Influence of ultrafine natural steatite powder on setting time and strength development of cement," Advances in Materials Science and Engineering, vol. 2014, Article ID 532746, 6 pages, 2014.

[13] M. Shanmugasundaram, S. Karthiyaini, and K. Sudalaimani, "Influence of ultrafine natural steatite powder on strength and permeability of high performance concrete," International Journal of Applied Engineering Research, vol. 10, no. 18, pp. 38967-38971, 2015. 
[14] M. Shanmugasundaram, R. Premkumar, R. Abinaya, KG. Arunya, M. Gowsalya, and M. Malathy, A new cement free binding material based on steatite powder activated through alkaline solution, Master Builder, 2016.

[15] E. Vela, M. Peiteado, F. García, A. C. Caballero, and J. F. Fernández, "Sintering behaviour of steatite materials with barium carbonate flux," Ceramics International, vol. 33, no. 7, pp. 1325-1329, 2007.

[16] T. Zhang, L. J. Vandeperre, and C. R. Cheeseman, "Formation of magnesium silicate hydrate (M-S-H) cement pastes using sodium hexametaphosphate," Cement and Concrete Research, vol. 65, pp. 8-14, 2014.

[17] EFNARC, Specification and Guidelines for Self-Compacting Concrete, European Federation of Producers and Applicators of Specialist Products for Structures, 2002.

[18] H. Tran and A. Scott, "Strength and workability of magnesium silicate hydrate binder systems," Construction and Building Materials, vol. 131, pp. 526-535, 2017.

[19] W. R. EUBANK, "Calcination Studies of Magnesium Oxides," Journal of the American Ceramic Society, vol. 34, no. 8, pp. 225229, 1951.

[20] T. Zhang, L. J. Vandeperre, and C. R. Cheeseman, "Magnesiumsilicate-hydrate cements for encapsulating problematic aluminium containing wastes," Journal of Sustainable CementBased Materials, vol. 1, no. 1-2, pp. 34-45, 2012.

[21] C. Wu, W. Chen, H. Zhang et al., "The hydration mechanism and performance of Modified magnesium oxysulfate cement by tartaric acid," Construction and Building Materials, vol. 144, pp. 516-524, 2017.

[22] H. Ma, B. Xu, and Z. Li, "Magnesium potassium phosphate cement paste: degree of reaction, porosity and pore structure," Cement and Concrete Research, vol. 65, pp. 96-104, 2014.

[23] S. L. Sarkar, "X-ray mapping - A supplementary tool in clinker phase characterization," Cement and Concrete Research, vol. 14, no. 2, pp. 195-198, 1984.

[24] C. Roosz, S. Grangeon, P. Blanc et al., "Crystal structure of magnesium silicate hydrates (M-S-H): The relation with 2:1 MgSi phyllosilicates," Cement and Concrete Research, vol. 73, pp. 228-237, 2015. 

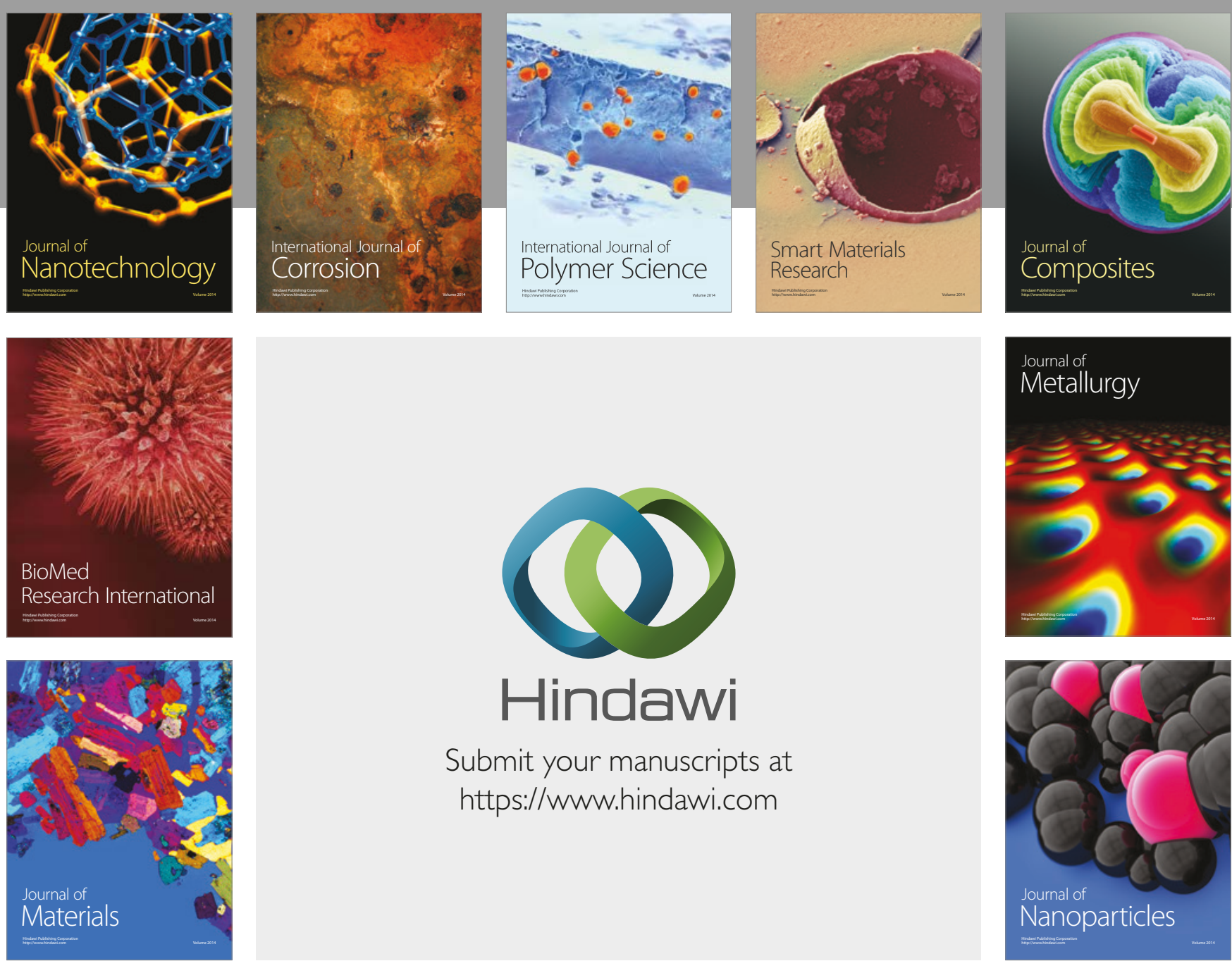

\section{Hindawi}

Submit your manuscripts at

https://www.hindawi.com
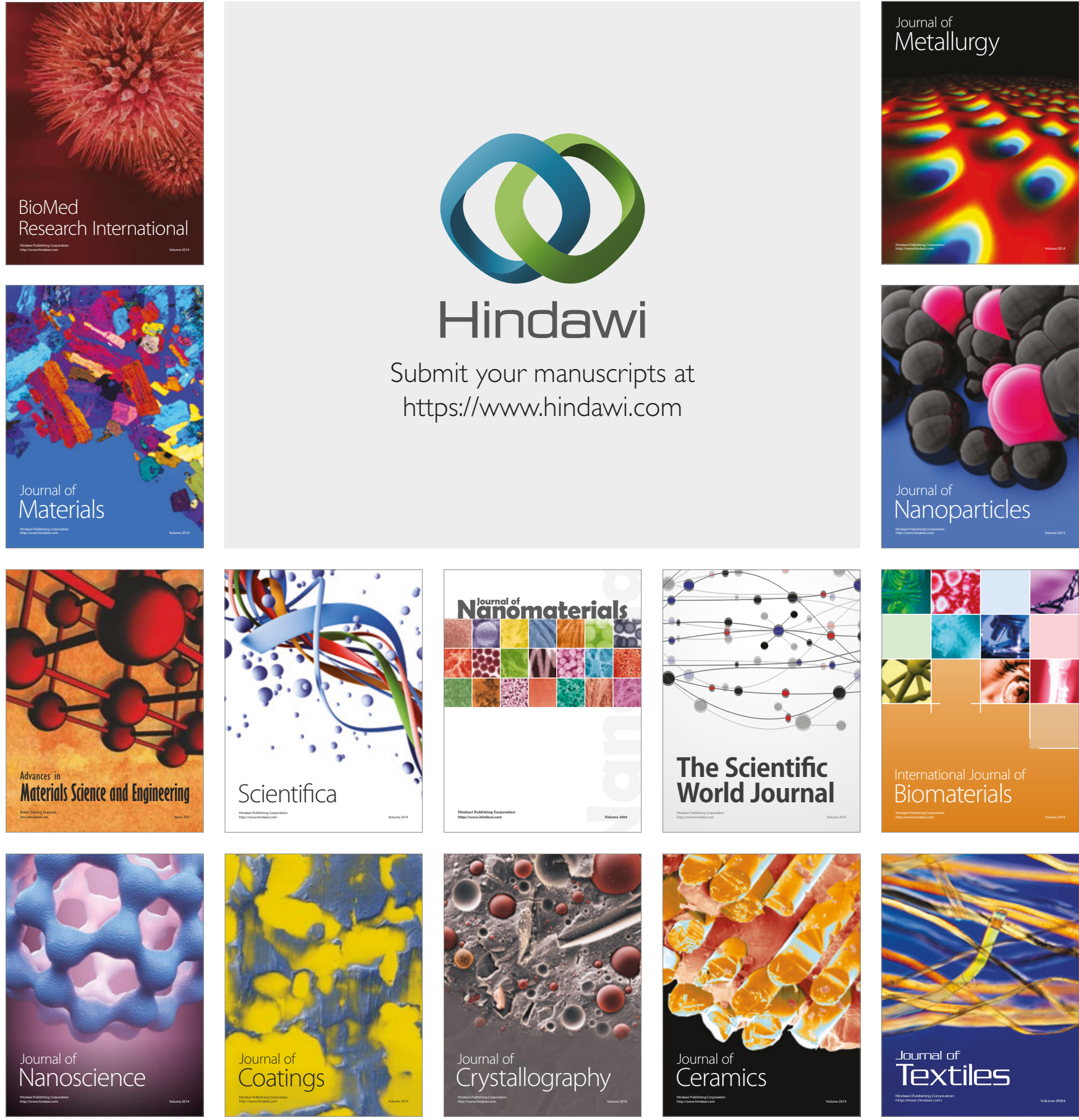

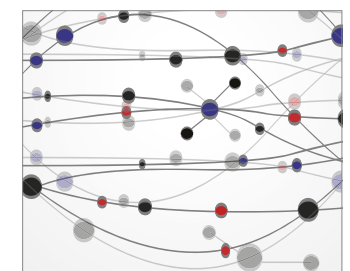

The Scientific World Journal
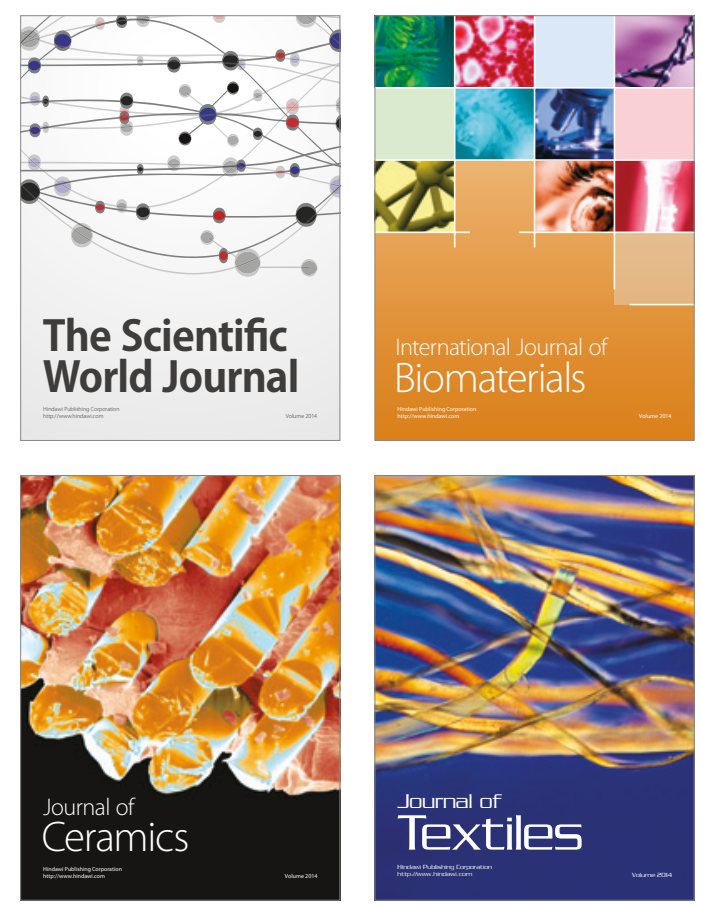